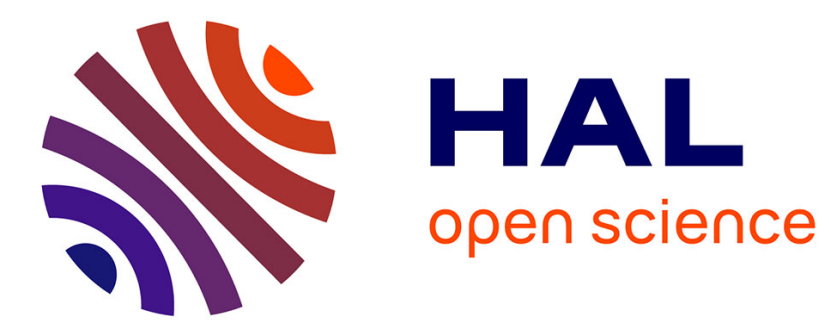

\title{
Cultivo in vitro de tejidos de tres especies de Stylosanthes (Leguminosae)
}

\author{
Hebe Y. Rey, Oscar A. Bovo, Luis A. Mroginski
}

\section{To cite this version:}

Hebe Y. Rey, Oscar A. Bovo, Luis A. Mroginski. Cultivo in vitro de tejidos de tres especies de Stylosanthes (Leguminosae). Agronomie, 1985, 5 (9), pp.819-824. hal-00884817

\section{HAL Id: hal-00884817 https://hal.science/hal-00884817}

Submitted on 1 Jan 1985

HAL is a multi-disciplinary open access archive for the deposit and dissemination of scientific research documents, whether they are published or not. The documents may come from teaching and research institutions in France or abroad, or from public or private research centers.
L'archive ouverte pluridisciplinaire HAL, est destinée au dépôt et à la diffusion de documents scientifiques de niveau recherche, publiés ou non, émanant des établissements d'enseignement et de recherche français ou étrangers, des laboratoires publics ou privés. 


\section{Cultivo in vitro de tejidos de tres especies de Stylosanthes (Leguminosae)}

Hebe Y. REY, Oscar A. BOVO \& Luis A. MROGINSKI

Instituto de Botánica del Nordeste (IBONE), Facultad de Ciencias Agrarias (UNNE), C.C. 209, Corrientes (3.400), Argentina

Plantas enteras de Stylosanthes macrosoma fueron obtenidas in vitro mediante el siguiente procedimiento : $1^{\circ}$ Inducción de callos por cultivo de explantos foliares en MS + ácido naftalenacético (ANA) $(1 \mathrm{mg} / \mathrm{l})+6$ bencilaminopurina (BAP) $(2 \mathrm{mg} / \mathrm{l}) .2^{\circ}$ Regeneración de vástagos en MS + ANA $(0,01 \mathrm{mg} / \mathrm{l})+$ BAP ( $1 \mathrm{mg} / \mathrm{l}) .3^{\circ}$ Enraizamiento de los vástagos en MS + ANA $(0,01 \mathrm{mg} / \mathrm{l})$. Con un procedimiento similar se obtuvieron vástagos de callos de entrenudos de $S$. montevidensis. En cambio, callos de láminas foliares de $S$. hippocampoides no regeneraron vastagos.

Palabras claves : Stylosanthes nippocampoides, Stylosanthes montevidensis, Stylosanthes macrosoma, callos, regeneracion de plantas.

Des plantes de Stylosanthes macrosoma sont régénérées à partir de folioles cultivées in vitro. Des cals se forment à partir des explants sur milieu de Murashige \& Skoog (MS) $+1 \mathrm{mg} / 1 \mathrm{ANA}+2 \mathrm{mg} / \mathrm{l}$ de 6-benzylaminopurine (BAP). On obtient des tigelles par transfert de fragments de cal sur milieu MS $+0,01 \mathrm{mg} / 1$ ANA $+2 \mathrm{mg} / \mathrm{l}$ BAP. Ces tigelles forment des racines sur milieu MS $+0,01 \mathrm{mg} / \mathrm{l}$ ANA. Sont également décrites la régénération de tigelles de $S$. montevidensis et l'induction de cals de $S$. hippocampoides.

Mots clés additionnels : Stylosanthes hippocampoides, Stylosanthes montevidensis, Stylosanthes macrosoma, cals, régénération de plantes.

Plants were regenerated from leaflets of Stylosanthes macrosoma cultured in vitro. Explants were induced to form callus when cultured on MS $+1 \mathrm{mg} / 1$ naphthaleneacetic acid (NAA) $+2 \mathrm{mg} / 1$ 6-benzylaminopurine (BAP). Regeneration of shoots was readily achieved by transferring pieces of callus onto a medium containing MS $+0.01 \mathrm{mg} / 1 \mathrm{NAA}+2 \mathrm{mg} / \mathrm{l}$ BAP. Shoots were induced to form roots upon transfer to MS $+0.01 \mathrm{mg} / \mathrm{l}$ NAA. Shoot regeneration of $S$. montevidensis and callus induction of $S$. hippocampoides are also described.

Additional key words : Stylosanthes hippocampoides, Stylosanthes montevidensis, Stylosanthes macrosoma, callus, plant regeneration.

\section{INTRODUCCION}

Las técnicas del cultivo in vitro de órganos, tejidos, células y protoplastos tienen múltiples aplicaciones en la agricultura para el logro de diversos objetivos como ser : micropropagación de plantas; obtención de plantas libres de patógenos; incremento de la variabilidad genética; conservación e intercambio de germoplasma. Para ello, los sistemas in vitro a emplearse deben posibilitar la regeneración de plantas enteras. En las Leguminosas estos sistemas son relativamente escasos (MroGINSKI \& KARTHA, 1984).

Con el género Stylosanthes - que contiene numerosas especies de valor forrajero - se han desarrollado algunos sistemas in vitro que permiten la regeneración de plantas a partir de callos. Scow- 
CROFT \& ADAMSON (1976) obtuvieron plantas de $S$. hamata por cultivos de cotiledones y radículas de semillas germinadas asépticamente. MROGINSKI \& KARTHA (1981) describieron un procedimiento para la obtención de plantas de $S$. guianensis a partir de callos de hojas. De igual modo se obtuvieron plantas de $S$. hamata, S. capitata y S. leiocarpa (MROGINSKI \& KARTHA, 1984). Paralelamente, MEIJER \& BROUGHTON (1981) y MEIJER (1982a) informaron sobre la regeneración de vástagos y plantas a partir de callos de $S$. guyanensis ( $=S$. guianensis, ver revisión de 'tMANNETJE, 1977) y recientemente, con esta especie, MEIJER \& STEINBISS (1983) obtubieron plantas a partir de suspensiones celulares y protoplastos. Asimismo, MEIJER (1982b) informó acerca de la regeneración de plantas de $S$. humilis a partir de callos obtenidos por cultivo in vitro de hojas e hipocótilos.

En el presente trabajo se describen los procedimientos que permiten la regeneración de vástagos de $S$. montevidensis y de plantas de $S$. macrosoma mediante el cultivo in vitro de entrenudos $\mathrm{y}$ de explantos foliares respectivamente.

\section{MATERIALES Y METODOS}

Se trabajó con Stylosanthes hippocampoides Mohl., $S$. montevidensis Vog. y $S$. macrosoma Blake. Todo este material se mantiene cultivado en macetas en la Facultad de Ciencias Agrarias (UNNE) y conservado en herbario (CTES).

Las hojas de $S$. hippocampoides y de S. macrosoma fueron desinfectadas por inmersión en etanol $70 \%$ durante unos pocos segundos, y luego en $\mathrm{NaClO}$ al 1,6\% (10 minutos), seguidos por varios lavados con agua destilada estéril. Posteriormente, los folíolos fueron cortados transversalmente en trozos de aproximadamente $6 \mathrm{~mm}^{2}$, los que fueron cultivados en tubos de ensayo de vidrio $(150 \times 15 \mathrm{~mm})$ conteniendo $5 \mathrm{ml}$ de medio de cultivo. Los tallos de $S$. montevidensis, previamente desinfectados de la manera descripta más arriba, fueron seccionados transversalmente $y$, porciones de los entrenudos de aproximadamente $5 \mathrm{~mm}$ de longitud fueron cultivados en tubos de ensayo de vidrio $(150 \times 15 \mathrm{~mm})$ conteniendo $5 \mathrm{ml}$ de medio de cultivo. En todos los casos se cultivó un explanto por tubo.

Para la inducción de cállos se utilizaron medios de cultivo compuestos de las sales minerales, vitaminas y sacarosa de acuerdo con MURASHIGE \& SKOOG, 1962 (MS), suplementado con sustancias reguladoras de crecimiento como ser : 6-bencilaminopurina (BAP), cinetina (KIN), 6 (gamma, gamma-dimetilalilamino)purina (2 iP), ácido indolacético (AIA), ácido 2,4diclorofenoxiacético (2,4-D) y ácido naftalenacético (ANA) en distintas combinaciones y concentraciones que se detallan en Resultados. Los medios fueron solidificados con agar al $0,8 \%$. El pH de los medios fue ajustado antes del agregado del agar a 5,8, con $\mathrm{NaOH} \mathrm{y} / \mathrm{o} \mathrm{HCl}$. Los medios de cultivo fueron esterilizados en autoclave a 1 atm de presión, durante 20 minutos.

Los cultivos fueron incubados en una cámara climatizada a una temperatura constante de $27 \pm 1^{\circ} \mathrm{C}$, con un fotoperíodo de $14 \mathrm{~h}\left(10 \mathrm{~W} / \mathrm{m}^{2}\right.$, suministrado por lámparas fluorescentes tipo «Grolux »).

Los callos obtenidos fueron subcultivados a medios frescos compuestos de MS suplementado con sustancias reguladoras de crecimiento que se detallan en Resultados. La incubación de los callos subcultivados fue llevada a cabo en las mismas condiciones descriptas para inducción de callos. Cada tratamiento consistió, en promedio, de 15 tubos y cada experiencia fue repetida, 3 veces.

\section{RESULTADOS}

\section{A. Cultivo de explantos foliares de $S$. hippocam- poides}

Al cabo de 10 días de incubación, comenzaron a visualizarse en varios medios de cultivo, los primeros callos los que, en su mayoría, al cabo de 30 días, cubrieron la superficie del medio de cultivo. Si bien, se obtuvieron callos en todas las combinaciones de hormonas ensayadas (Tabla 1), el mayor crecimiento de los callos se consiguió con ANA $1 \mathrm{mg} / \mathrm{l}$ combinado con BAP a 1,2 ó $3 \mathrm{mg} / \mathrm{l}$. En general, los callos tuvieron un crecimiento rápido, presentando una superficie lisa y de consistencia mucilaginosa.

Los callos o porciones de los mismos fueron subcultivados en diferentes medios compuestos de MS suplementados con diferentes combinaciones entre auxinas (ANA, AIA ó $2,4-\mathrm{D}$ ) a $0,01 \mathrm{mg} / \mathrm{l}$ y citocininas (BAP, KIN ó 2 iP) en concentraciones de 1,3 y $5 \mathrm{mg} / \mathrm{l}$. En ninguno de los medios hubo diferenciación ni de vástagos ni de plantas enteras, aún luego de 60 dias de cultivo.

\section{B. Cultivos de entrenudos de $S$. montevidensis}

Luego del octavo día de cultivo, en los extremos cortados de los entrenudos, comenzaron a visualizarse pequeñas masas callosas de color verde intenso para, posteriormente adquirir una coloración amarilla con pequeñas áreas verdes. Al cabo de 30 días de incubación, en todos los medios ensayados (tabla 1), los callos cubrían la superficie de los medios.

Los callos o porciones de los mismos fueron subcultivados en MS + ANA 0,01 mg/l + BAP $3 \mathrm{ml} / \mathrm{l}$. Luego de 30 días, en el $29 \%$ de los callos se diferenciaron múltiples vástagos (3-5 vástagos por callo). En promedio, cada vástago medía $4 \mathrm{~cm}$. Con el objeto de inducir su enraizamiento, los vástagos fueron transferidos a MS desprovisto de reguladores $o$ a MS + ANA 0,01 mg/l. En ningún caso se logró la inducción de raíces.

\section{Cultivos de explantos foliares de $S$. macrosoma}

La aparición de callos en los explantos comenzó durante la segunda semana de cultivo. La proliferación callosa, que se inició en los bordes de los explantos, inicialmente era de consistencia friable y de color blanco para luego volverse más compacta y de color amarillo y/o marrón con áreas verdes. Los resultados obtenidos a los 30 días de incubación muestran que todos los medios ensayados (tabla 1) 
TABLA 1

Inducción de callos por cultivo de explantos foliares de Stylosanthes hippocampoides y de S. macrosoma y de entrenudos de $\mathrm{S}$. montevidensis. 30 dias de incubacion.

Callus induction from leaves of Stylosanthes hippocampoides and $\mathrm{S}$. macrosoma and callus induction from internodes of $\mathrm{S}$. montevidensis after 30 days culture.

\begin{tabular}{|c|c|c|c|c|c|c|}
\hline \multicolumn{3}{|c|}{ Hormonas (mg/l) } & \multirow{2}{*}{$\frac{\text { S. hippocampoides }}{\% \% \text { de callos }}$} & \multirow{2}{*}{$\begin{array}{l}\text { S. montevidensis } \\
\% \text { de callos }\end{array}$} & \multicolumn{2}{|c|}{ S. macrosoma } \\
\hline ANA & BAP & KIN & & & $\%$ de callos & Peso seco/callo ${ }^{x x}$ \\
\hline 0.01 & 1 & 0 & 76 & $-\underline{x}$ & 100 & + \\
\hline 0.01 & 2 & 0 & 68 & --- & 100 & + \\
\hline 0.01 & 3 & 0 & 59 & ... & 83 & + \\
\hline 0.1 & 1 & 0 & 72 & -.- & 80 & ++ \\
\hline 0.1 & 2 & 0 & 70 & --- & 75 & $+t$ \\
\hline 0.1 & 3 & 0 & 64 & ... & 81 & ++ \\
\hline 1 & 1 & 0 & 98 & 91 & 100 & +++ \\
\hline 1 & 2 & 0 & 100 & 85 & 100 & $++t$ \\
\hline 1 & 3 & 0 & 88 & 80 & 100 & ++ \\
\hline 0.01 & 0 & 2 & -- & 63 & -- & --- \\
\hline 0.1 & 0 & 2 & --- & 61 & --- & --- \\
\hline 1 & 0 & 2 & -.. & 84 & --. & -.- \\
\hline
\end{tabular}

Referencias : x (--) : combinaciones no ensayadas $; \mathrm{xx}:+=$ hasta $25 \mathrm{mg}$ de peso seco $;++=26-50 \mathrm{mg}$ de peso seco $;+++=51-75 \mathrm{mg}$ de peso seco.

posibilitan la producción de callos (fig. 1a) en altos porcentajes de los explantos cultivados (75 a $100 \%$ ). Sin embargo, el tamaño de los callos, evaluado como peso seco, dependió de las concentraciones de las hormonas empleadas. Los valores más altos de peso seco fueron logrados en los medios compuestos de MS y ANA $1 \mathrm{mg} / 1$ combinado con BAP 1 ó $2 \mathrm{mg} / \mathrm{l}$.

Con el objeto de inducir la proliferación de vástagos, porciones de los callos originados en MS suplementado con ANA $1 \mathrm{mg} / \mathrm{l}$ y con tres concentraciones de BAP $(1,2$ y $3 \mathrm{mg} / \mathrm{l})$, fueron transferidos a medios frescos (《medios de regeneración »). Los resultados obtenidos entre 45 y 60 dias de cultivo (tabla 2) muestran que, en varios medios, los callos diferenciaron múltiples vástagos (en promedio, 4 vástagos por callo) de entre 1 y $3 \mathrm{~cm}$ de longitud (fig. 1b). Los mayores porcentajes de callos que produjeron vástagos fueron obtenidos en MS + ANA $0,01 \mathrm{mg} / 1+$ BAP 1 ó $3 \mathrm{mg} / \mathrm{l}$, independientemente del medio de cultivo que dio origen a los callos. En ningún medio hubo diferenciación de raíces.

Para inducir su enraizamiento, los vástagos fueron transferidos a un medio de cultivo compuesto de MS + ANA $0,01 \mathrm{mg} / \mathrm{l}$ donde, al cabo de 7 días se pudo apreciar la formación de raíces (fig. $1 c$ ) en el $62 \%$ de los vástagos. Las plantas obtenidas fueron exitosamente transferidas a macetas.

\section{DISCUSSION}

Este trabajo muestra que la capacidad regeneradora de plantas de los callos originados por cultivo in vitro de láminas foliares y entrenudos de tres especies de Stylosanthes, es diferente según sea la especie considerada. A pesar de los esfuerzos realizados no fue posible la obtención ni de vástagos, ni de plantas enteras a partir de callos de $S$. hippocampoides. En

\section{TABLA 2}

Efecto de los medios inductores de callos y de los medios de regeneración sobre la diferenciación de vástagos de Stylosanthes macrosoma. Effect of callus induction und regeneration media on shoot differentiation in Stylosanthes macrosoma.

\begin{tabular}{|c|c|c|c|c|}
\hline \multirow[b]{2}{*}{$\begin{array}{l}\text { Medio de inducción } \\
\text { de callos }\end{array}$} & \multicolumn{4}{|c|}{$\%$ de callos que regeneran vástagos } \\
\hline & MS & $\mathrm{MS}+\mathrm{BAP} 1 @$ & $\mathrm{MS}+\mathrm{ANA} 0.01+\mathrm{BAP} 1$ & $\mathrm{MS}+\mathrm{ANA} 0.01+\mathrm{BAP} 3$ \\
\hline $\mathrm{MS}+\mathrm{ANA} 1 \stackrel{\text { B }}{+}+\mathrm{BAP} 1$ & 0 & 0 & 17 & 50 \\
\hline $\mathrm{MS}+\mathrm{ANA} 1+\mathrm{BAP} 2$ & 0 & 11 & 58 & 33 \\
\hline $\mathrm{MS}+\mathrm{ANA} 1+\mathrm{BAP} 3$ & 0 & 0 & 37 & 36 \\
\hline
\end{tabular}




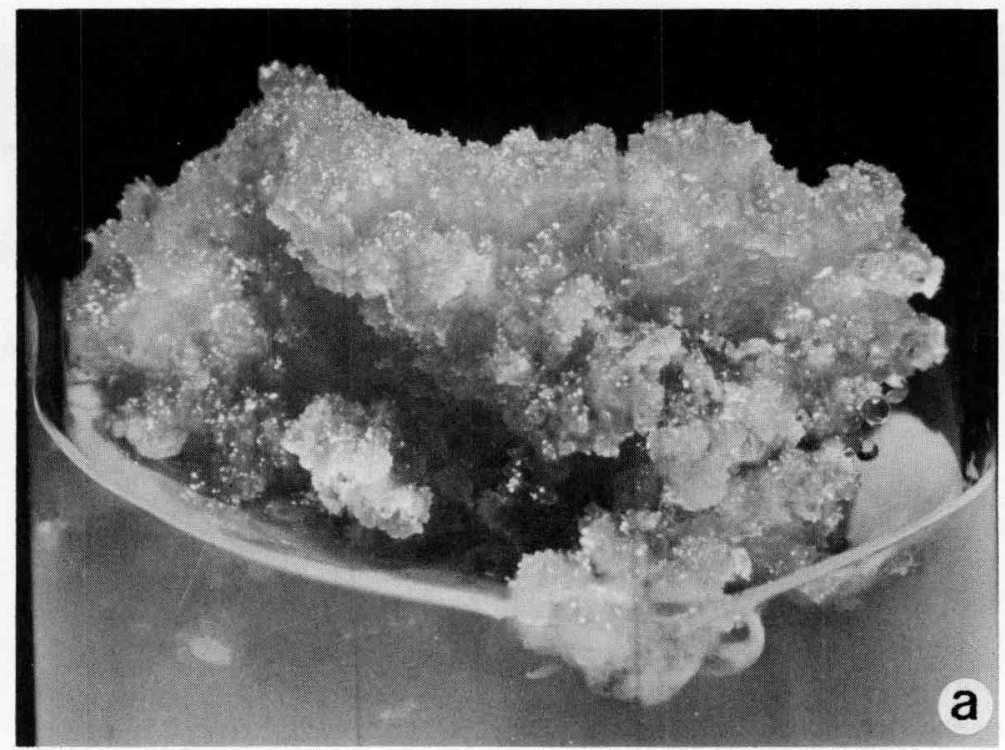

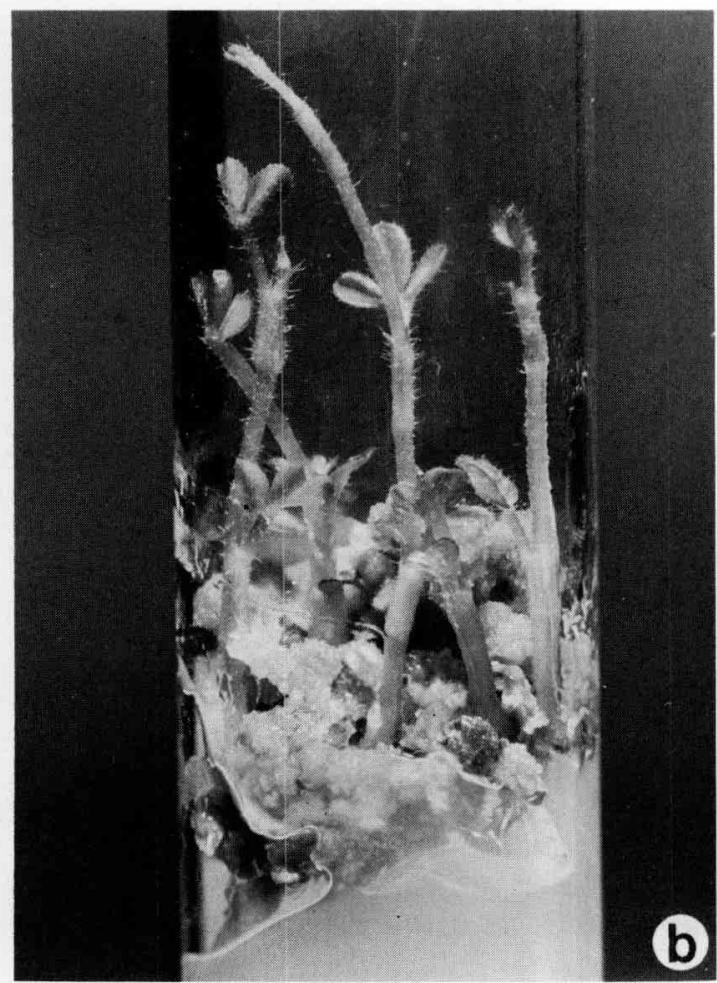

Figure 1

Regeneración in vitro de plantas de Stylosanthes macrosoma. a) Inducción de callos en $M S+A N A 1 m g / l+B A P 2 m g / l$ ( $\times$ 7). b) Regeneración de vástagos en callos subcultivados en $M S+A N A 0,01 \mathrm{mg} / l+B A P I m g / l(\times 3)$. c) Enraizamiento de los vástagos en $M S+A N A 0,01 \mathrm{mg} / \mathrm{l}(\times 1,5)$.

cambio los callos de $S$. montevidensis regeneraron vástagos pero éstos no pudieron ser enraizados; mientras que los callos de S. macrosoma diferenciaron vástagos que fueron enraizados y transferidos al suelo. Este comportamiento diferencial entre especies de un mismo género es un hecho común con el cultivo in vitro de tejidos e inclusive ha sido encontrado a nivel de variedades de $S$. guianensis (MEIJER, 1982a; MROGINSKI \& KARTHA, no publicado).

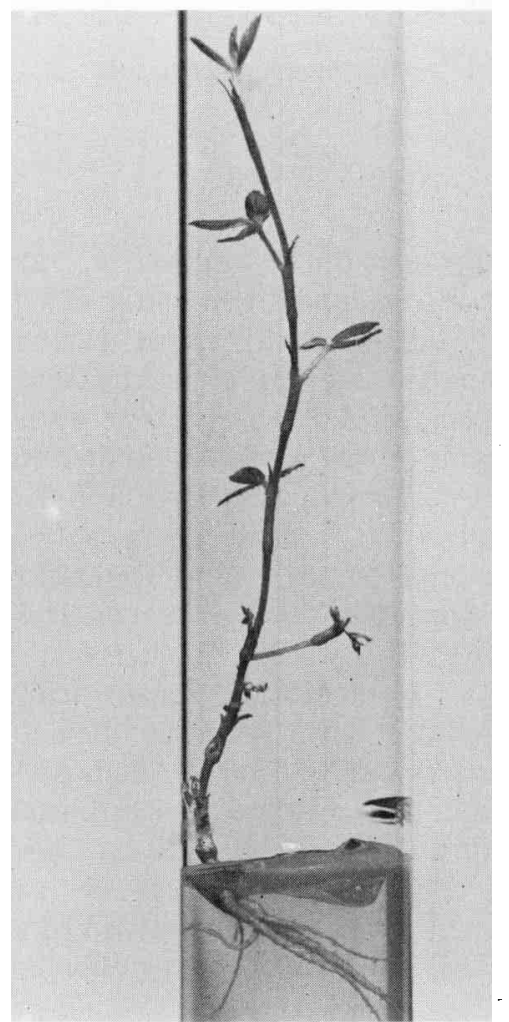

C

In vitro plant regeneration of Stylosanthes macrosoma. a) Callus induction on $M S+1 \mathrm{mg} / \mathrm{lNAA}+2 \mathrm{mg} / \mathrm{l} B A P(\times 7)$. b) Shoot regeneration from subcultured calli on $M S+0.01 \mathrm{mg} / \mathrm{NA} A$ $+I m g / l B A P(\times 3)$. c) Rooting of shoots on $M S+0,01 \mathrm{mg} / /$ $N A A(\times 1.5)$.

Es probable que el objetivo de obtener plantas enteras a partir de callos de $S$. montevidensis pueda ser alcanzado a corto plazo, dado que únicamente resta desarrollar la técnica que posibilite el enraizamiento de los vástagos obtenidos in vitro aunque es necesario señalar que esta última etapa, aparentemente simple, limita la obtención de plantas in vitro de especies de un género estrechamente relacionado con Stylosanthes como lo es el género Arachis 
(Mroginski \& FernandeZ, 1980 ; Mroginski et al., 1981). Es interesante destacar que en el caso de $S$. montevidensis se cultivaron explantos provenientes de los entrenudos porque, por un lado, de esta manera se obtenía un mayor número de explantos que si se utilizaban hojas. Por otra parte, con el empleo de explantos foliares, la frecuencia de cultivos infectados con microorganismos fue siempre elevada.

Finalmente, los resultados de este trabajo permiten incorporar a Stylosanthes macrosoma en la lista de especies vegetables con las que la regeneración de plantas enteras a partir de callos es factible.

\section{Reçu le 20 décembre 1984.} Accepté le 30 mai 1985.

\section{AGRADECIMIENTOS}

A Ricardo O. VANNI, por su colaboración en la recolección e identificación del material vegetal, y a $\mathrm{H}$. VÁzQUEZ por la confección de las fotografías.

\section{REFERENCES}

Meijer E. G. M., 1982a. Shoot formation in tissue cultures of three cultivars of the tropical pasture legume Stylosanthes guyanensis (Aubl.). Sw. Z. Pflanzenzüchtg., 89, 169-172.

Meijer E. G. M., 1982b. High-frequency plant regeneration from hypocotyl-and leaf- derived tissue cultures of the tropical pasture legume Stylosanthes humilis. Physiol. Plant. 56, 381-385.

Meijer E. G. M., Broughton W. J., 1981. Regeneration of whole plants from hypocotyl-, root-, and leaf-derived tissue cultures of the pasture legume Stylosanthes guyanensis. Physiol. Plant., 52, 280284.

Meijer E. G. M., Steinbiss H.-H., 1983. Plantlet regeneration from suspension and protoplast cultures of the tropical pasture legume Stylosanthes guyanensis (Aubl.). Sw. Ann. Bot., 52, 305-310.

Mroginski L. A., Fernandez A., 1980. Obtención de plántulas por cultivo in vitro de anteras de especies silvestres de Arachis (Leguminosae). Oléagineux, 35, 89-92.

Mroginski L. A., Kartha K. K., 1981. Regeneration of plants from callus tissue of the forage legume Stylosanthes guianensis. Plant Sci. Lett., 23, 245-251.
Mroginski L. A., Kartha K. K., 1984. Tissue Culture of Legumes for Crop Improvement, p. 215-264. In J. Janick : « Plant Breeding Reviews, Vol. 2 ". The AVI Publ. Co. Inc. Westport, CT, USA, $327 \mathrm{p}$.

Mroginski L. A., Kartha K. K., Shylık J. P., 1981. Regeneration of peanut (Arachis hypogaea) plantlets by in vitro culture of immature leaves. Can. J. Bot., 59, 826-830.

Murashige T., Skoog F., 1962. A revised medium for rapid growth and bioassays with tobacco tissue cultures. Phrsiol. Plant., 15, 473497.

Scowcroft W. R., Adamson J. A., 1976. Organogenesis from callus cultures of the legume, Stylosanthes hamata. Plant Sci. Lett., 7, 3942 .

'Mannetje L., 1977. A revision of varieties of Stylosanthes guianensis (Aubl.). Sw. Aust. J. Bot., 25, 347-362. 